\title{
The Arabic Aspectual Marker Qad from the Perspective of the Two- Component Theory of Aspect
}

\author{
Dania Adel Salamah \\ King Saud University
}

\begin{abstract}
Correspondence concerning this review article should be addressed to Dania Adel Salamah, Department of English Language and Translation, College of Languages and Translation, King Saud University, 11472. E-mail: dsalamah@ksu.edu.sa
\end{abstract}

\begin{abstract}
The study examined the Arabic aspectual particle qad within the framework of Smith's TwoComponent Theory of Aspect, which views aspectual meaning as a combination of covert situation types and overt viewpoint markers. The analysis, which was conducted on Modern Standard Arabic, revealed that the Arabic aspectual marker qad has a tendency to be used perfectively, but it also has imperfective uses. However, as far as situation types are concerned, the analysis found some variation when it comes to the use of imperfective and perfective qad. The findings were also correlated to different constructions in which qad typically occurs.
\end{abstract}

Keywords: aspect in modern standard Arabic, aspectual meaning, aspectual particle qad, translation, two-component theory of aspect, verb semantics

\section{Introduction}

Languages usually have a system to indicate tense, which is a means for relating the time of an event to another time (Comrie, 1976). They also have a means to indicate aspect (Hamm \& Bott, 2016), which expresses information about how an event unfolds over time (Cruse, 2011). Some languages formally distinguish between three tenses: the present, past, and future (Comrie, 1976), while others only distinguish between past and nonpast tenses (Gadalla, 2006).

Further, aspect is viewed as a two-fold notion; namely, lexical aspect and grammatical aspect. Anderson (1991) has indicated that lexical aspect is related to the inherent sense of the verb or situation, while grammatical aspect depends on grammatical marking. Cruse (2011) has also made a distinction between semantic aspect and aspect markers. The distinction proposed by Cruse (2011) roughly corresponds to Anderson's (1991). Anderson's (1991) lexical or inherent aspect resembles Cruse's (2011) semantic aspect; both view aspect from the perspective of the senses contributed by the verb or situation. Moreover, Anderson's (1991) grammatical aspect is similar to Cruse's (2011) aspect markers since they both refer to the grammatical markers languages use to indicate aspectual meaning (e.g., inflections, auxiliaries, particles).

This article is composed of four main sections. After this brief introduction, the purpose of the study is outlined. Section 1 is devoted to discussing relevant literature including the tense and aspect system of Modern Standard Arabic (MSA), the Arabic particle qad, and the notion of aspectual meaning with a focus on Smith's (1997) Two-Component Theory of Aspect. The procedures of the study are presented in Section 2. Finally, the paper is concluded with a discussion of the findings in Section 3 followed by the conclusion in Section 4.

This study is situated within the sub-field of semantics that is concerned with examining grammatical meaning. More specifically, it deals with aspectual meaning, which is linked to verbal notions (Cruse, 2011). The purpose of the study was to investigate the behavior of the Arabic aspectual marker qad within the framework of Smith's (1997) Two-Component Theory of Aspect. The aspectual system of Arabic is mainly realised by the use of grammatical devices such as auxiliaries, particles, and affixes. The particle qad was selected as the focus of the current study because it is involved in creating compound tenses in Arabic (Ryding, 2005). These compound tenses include both perfective and imperfective constructions that express temporal meanings similar to those conveyed by some English tenses. 
The Two-Component Theory of Aspect was selected as the theoretical framework of the present study because of its "explanatory power" (Shirai, 2000, p. 333). Smith (1997) herself has applied the theory to the aspectual systems of English, French, Russian, Mandarin Chinese, and Navajo. It has also been used to investigate elements of the aspectual systems of Japanese (Shirai, 2000) and Hungarian (Csirmaz, 2008).

In addition to contributing to the area of verb semantics by addressing the Arabic aspectual marker qad, the analysis itself could have pedagogical implications to those in the field of translator training. Translation students face difficulties in translating from English into Arabic and vice versa. It is challenging on several levels, especially when it comes to the translation of tense and aspect, due to the big difference between the tense/aspect systems of English and Arabic (Gadalla, 2017; Sieny, 1986). This is mainly because of the highly structured tense/aspect system in English as opposed to Arabic, as Gadalla explained, "whereas the Arabic verb has two aspectual forms, the English verb has sixteen tenses" (2017, p. 10). Translators usually overcome this challenge by using lexical and grammatical devices (e.g., particles, affixes, auxiliaries). Investigating the senses associated with the use of the particle qad may help identify the English constructions that are more compatible with Arabic.

It is worth noting at this point that the researcher adopted the transcription system employed by the Library of Congress. ${ }^{1}$

\section{Literature Review}

This section is introduced with a general discussion of tense and aspect. Then it addresses the tense and aspect system of MSA, which is followed by a more detailed overview of the Arabic particle qad. The literature review is concluded by a discussion of the literature relevant to aspectual meaning, with an emphasis on Smith's (1997) Two-Component Theory of Aspect.

\section{Tense and Aspect}

The study of tense and aspect systems has been of interest to researchers for many years. Different scholars have addressed the two notions from a variety of perspectives (e.g., Comrie, 1976; Dragoy, Virfel, Yurchenko \& Bastiaanse, 2019; González \& Hernández, 2018; Izquierdo \& Kihlstedt, 2019; Kanwit, 2017; Smith; 1997). Since tense and aspect are two intertwined notions, a discussion of tense is appropriate when any discussion of aspect is attempted. For this reason, this section addresses tense before turning to aspect.

As mentioned earlier, tense is a means of relating the time of an event to another point in time, which is usually the time of speaking or utterance time (Comrie, 1976; Cruse, 2011). Within the notion of tense (Comrie, 1976; Cruse, 2011), a distinction has been made between absolute tense and relative tense. Absolute tense relates a point in time to the time of speaking (e.g., English present, past, and future), while relative tense relates a point in time to another event or time (e.g., English past perfect). In this sense, relative tense does not directly relate an event to time of speaking, while absolute tense does.

The notions of tense and aspect are intertwined, as noted above. Cruse has emphasised the difference explaining, "aspect says nothing about when an event occurred [...], but either encodes a particular way of conceptualising an event or conveys information about the way the event unrolls through time" (2011, p. 299). Comrie (1976) has also indicated that aspect deals with the internal temporal make-up of an event, while tense deals with its external temporal location. Accordingly, he defined aspect as "the different ways of viewing the internal temporal constituency of a situation" (Comrie, 1976, p. 3).

A difference in aspect, for instance, can be detected in the English examples I studied and I was studying. Even though both examples convey absolute past tense, the difference is clear in describing the activity of studying in each example. The first example I studied describes an action that is viewed as a complete whole without considering its different stages. The second example, on the other hand, emphasises the duration of the event and entails looking at the event from within. The two examples illustrate a basic distinction between perfective and imperfective aspect. Thus, perfective aspect views an event as a single unit. Conversely, imperfective aspect conceptualises events as having occurred over a period of time, and it allows participants to view them from within (Comrie, 1976).

\footnotetext{
${ }^{1}$ The Library of Congress. (2012). ALA-LC Romanization tables. Retrieved from http://www.loc.gov/catdir/cpso/roman.html
} 
In his discussion of aspect, Dahl addressed what he referred to as "the perfective: imperfective opposition" (1985, p. 69) claiming that investigations in this area have mainly attempted to identify the mutual characteristics of the notion of perfectivity in different languages from a semantic point of view. Accordingly, he explained that variation exists in the underlying meanings expressed by the notion of perfectivity although there are shared features. Nevertheless, Dahl (1985) argues that perfective aspect prototypically conflates with past time.

Another distinction in aspect or aspectual meaning has been made between semantic meaning and the formal or grammatical markers of aspect that vary from one language to another. This is discussed in further detail under Smith's (1997) Two-Component Theory of Aspect below. The Two-Component Theory of Aspect theory is one of the approaches that consider both semantic meaning and formal aspectual markers, and it is the theoretical framework within which the present investigation was conducted.

\section{Tense and Aspect in MSA}

MSA, which has also been referred to as Modern Literary Arabic (Haywood \& Nahmad, 1965) and Modern Written Arabic (Badawi, Carter, \& Gully, 2016), is the variety of Arabic currently used across the Arab world in writing as well as public speaking, the media, and education (Ryding, 2005). The present study deals with aspect in MSA, but not in the regional or other variations that exist across the Arab world. Thus, different varieties may employ different means for expressing the notions of tense and aspect even though they are all varieties of the Arabic language.

As far as verb forms are concerned, native speakers of Arabic are formally taught to distinguish between past, present, and imperative verb forms in line with Sibawayh's tradition (Gadalla, 2006). However, since the imperative is not a temporal notion, it shall not be dealt with in the present discussion. In Arabic, temporal meaning is conveyed by past and present-or more precisely, past and non-past verb forms, which are referred to in Arabic as al-mādì and al-mudâari ', respectively. The two terms past and non-past will be used throughout this paper to refer to the Arabic verb forms $a l-m \bar{a} d \bar{l}$ and $a l-m u d \underline{a} r i$ ', respectively. The non-past form of the verb is also used to indicate future tense in MSA. It may occur with temporal adverbials that carry a future reference. Otherwise it may be combined with particles and affixes such as the particle sawfa and the prefix sa-, which are used to convey future time in MSA. In their discussion of the grammar of Arabic, Badawi, Carter, and Gully (2016) commented:

There is not an elaborate system of sequences of tenses, and the underlying principle remains basically aspectual, that is, an event which is regarded as having ceased before another will be in the perfect, while an event regarded as still going on will be in the imperfect. The head verb will determine the time and aspect frame of the whole discourse unit. (p. 419)

Different scholars have argued that Arabic past and non-past correspond to perfective/perfect and imperfective/ imperfect aspect, respectively (Comrie, 1976; Gadalla, 2006; Gadalla, 2017; Haywood \& Nahmad, 1965; Ryding, 2005). Haywood and Nahmad (1965) and Caspari (1898) have agreed that the perfect form is used to denote finished or completed acts, while the imperfect form is used to indicate incomplete acts. Nevertheless, some scholars have argued that the notions of perfective and imperfective combine both tense and aspect (Bahloul, 2008; Comrie, 1976). This means that past and non-past Arabic verb forms are used to express aspectual differences in meaning as well as temporal information. This has been echoed by Ryding as she explained that tense and aspect overlap in MSA, which is emphasised by the tendency of teachers "to describe Arabic verbs in terms of tense" (2005, p. 52). However, Gadalla stated, "in Arabic, the fundamental differences between verbs are based on aspect rather than tense" (2017, p. 9). Bahloul (2008) has even proposed that Arabic does not have a detailed system of aspect or tense. Conversely, Badawi, Carter, and Gully (2016) maintain that Arabic has an aspect system composed of perfect and imperfect, in addition to a tense system comparable to the tense systems of Western languages. They explained that the complex tenses of Western languages are expressed in Arabic when perfect and imperfect forms are combined with other elements.

Examples (1) to $(8)^{2}$ below present Arabic constructions equivalent to some English tense constructions.

\footnotetext{
${ }^{2}$ Examples (1) to (7) are adapted from Fassi Fehri (2012). Example (8) is adapted from Comrie (1976).
} 
(1) ya rifu al-jawāb

He knows the answer.

(simple present)

(2) yaktubu al-risālata

writes he the-letter

He is writing the letter.

(present progressive)

(3) kataba al-risālata

wrote he the-letter

He wrote the letter.

(simple past)

(4) kāna yaktubu al-risālata

was he writes he the-letter

He was writing the letter.

(past progressive)

(5) yaqta'u al-rajulu al-masāfata ghadan fì sā'atin

crosses he the-man the-distance tomorrow in an-hour

The man will cross the distance tomorrow in an hour.

(simple present)

(6) ad $a t \bar{a}$

qad came he

He has (just) come.

(present perfect)

(7) kāna qad kataba al-risālata

crosses he qad wrote he the-letter

He had (already/just) written the letter.

(past perfect)

(8) sa-yakūnu qad atā
will be he qad came he

He will have (already) come.

(future perfect)

Temporal notions that are comparable to English simple and progressive present forms are formulated in Arabic using the non-past form of the verb as in examples (1) and (2) without the addition of any particles, auxiliaries, or affixes. However, it is worth noting that the differences in aspect in examples (1) and (2) above are due to the senses contributed by the verbs in both examples; they are not structural. The past form of the Arabic verb is used to express the meaning of simple past as in example (3), while the non-past form is used along with the past form of the auxiliary kāna-the Arabic equivalent of the English auxiliary be-as illustrated in example (4), to indicate imperfective past (i.e., English past progressive). The non-past verb form is used in the construction expressing future time as in example (5). However, the presence of a supporting context (i.e., the adverbial ghadan, which means 'tomorrow') is responsible for future time reference in this case. Examples (6), (7), and (8) represent perfect constructions otherwise referred to by Ryding (2005) as compound tenses. Some of the temporal and aspectual notions that are similar-but not equivalent-to those expressed by English perfect constructions (e.g., present, past, and future perfect) are conveyed in MSA using constructions that typically include the particle qad and/or a form of the auxiliary kāna.

It is worth noting that due to the absence of context, some of the examples may be translated differently. For instance, example (6), translated here as He has (just) come, may also be translated as He (just) came. This variation in translating constructions that include qad has been addressed by Gadalla (2017) in a corpus-based study. His analysis confirmed that there is no one-to-one correspondence between qad constructions and specific English constructions. According to his investigation, such constructions are translated using a variety of English tenses to perform different functions. For instance, based on his data, the Arabic construction qad + past form of verb was translated using-in order of frequency-English past simple, present simple, present perfect, past perfect, and past progressive, while the construction kāna + qad + past form of verb was typically translated using English past perfect (i.e., 80\%). The past simple and the present perfect were also used but at much lower frequencies. Further, Gadalla (2017) explained that the construction sa-/sawfa + non-past form of $k \bar{a} n a+q a d+$ past form of verb is usually translated using the English future perfect or future perfect progressive. 
Another construction discussed by Gadalla (2017), which is relevant to the present study, is the construction qad + kāna + non-past form of verb. He equates it to the English past progressive. Nevertheless, Gadalla (2017) only addresses this construction based on a single occurrence in the data. However, due to the variation in the translation of other constructions that contain qad in Gadalla's (2017) data, it may be safe to assume that the same type of variation would be detected if more instances of this construction were to be analysed.

\section{The Arabic Particle Qad}

The Arabic particle qad is associated with several meanings. According to Bahloul (2008), Arabic language scholars have considered it from three different angles. He elaborated that the particle qad has been examined from temporal, aspectual, and modal perspectives. He discussed each of these approaches-or hypotheses, as he referred to them-illustrating different cases under each. In the temporal hypothesis, when the particle qad occurs with the past form of the verb, an additional meaning of recent past is portrayed as opposed to the verb's use without qad, in which case the temporal information conveyed is before the time of utterance without any reference to whether the event was recent or otherwise. In his presentation of the aspectual hypothesis of $q a d$, he explained that its use with the past form of the verb indicates completed actions. Finally, he touched upon the emphatic hypothesis-or modal function-of qad equating it with the functions of the English auxiliary $d o$, which carries the meaning of certainty. He also commented that this last hypothesis has received the most attention among Arabic language scholars.

The discussion presented by Bahloul (2008) was also presented and extended by Michalski (2011). Although the main purpose of Michalski (2011) was to distinguish the functions of the compound particle la-qad from those of $q a d$, he reviewed the three hypotheses proposed by Bahloul (2008) adding to them an informational hypothesis and a multifunctional hypothesis. The informational hypothesis is concerned with occurrences that introduce either conflicting or background information. The multifunctional hypothesis, on the other hand, deals with the functions of qad in Classical Arabic and MSA. Under this hypothesis, Michalski (2011) addressed a discourse analysis approach to la-qad as a discourse marker.

Qad has also been explored by Fassi Fehri (2012) who categorised its uses broadly into temporal and modal. According to Fassi Fehri (2012), when qad is used as a temporal marker, it prefers the perfect interpretation, typically carrying the meaning of precedence or immediate precedence. As a modal, qad indicates certainty when combined with a past verb form and possibility or probability when combined with a non-past verb form.

In sum, the particle qad occurs with both past and non-past forms of Arabic verbs to perform functions that may be temporal/aspectual or modal. Under its temporal/aspectual functions, qad typically prefers the perfect interpretation of completed actions when occurring with past verb forms. The modal functions of qad portray varying degrees of certainty which are also determined by the verb form with which it occurs. Modal qad typically conveys certainty when combined with past verb forms, and probability or possibility when combined with non-past verb forms. Nevertheless, indicating certainty with modal qad and the past form of the verb entails conveying a perfect interpretation as well. Of course, the presence of context also plays a crucial role in determining the functions and the senses expressed by qad. In fact, in a corpus-based study of the functions of qad, Farghal (2019) claims that the discourse dictates whether the past form of the Arabic verb is used with or without qad. It is worth noting at this point that no distinction will be made in the present study between qad/ la-qad in line with Gadalla's approach (2017). Further, the modal function of qad will not be addressed since it is not the focus of the current study.

\section{Aspectual Meaning and Smith’s Two-Component Theory of Aspect}

In the literature on aspectual meaning, many researchers have distinguished between semantic aspect and formal or grammatical aspect. For instance, Dahl (1985) distinguished between Aktionsart, or inherent aspectual meaning, and morphological forms. Anderson (1991) referred to the two notions as inherent aspect and grammatical aspect, Smith (1997) as situation types and viewpoints, and Li and Shirai (2000) as lexical aspect and grammatical aspect. Even though different terminology has been used, Xiao and McEnery maintain that "the distinction between situation aspect and viewpoint aspect is recognised by many authors" (2004, p. 18).

From a semantic perspective, aspect has been the focus of several researchers as well (e.g., Hay, Kennedy, \& 
Levin, 1999; Peck, Lin, \& Sun, 2013; Rappaport Hovav \& Levin, 2010; Xiao \& McEnery, 2004). Nevertheless, such studies mainly set out to describe particular dimensions of aspectual use, or else they aimed at describing the aspectual system of a particular language. In fact, some of them have drawn on Smith's (1997) Two-Component Theory of Aspect in one way or another. For example, Peck, Lin, and Sun (2013) elaborated on Smith (1997) by adding the aspectual feature [+/- scale] to describe aspect in Mandarin Chinese. Xiao and McEnery (2004), also adopting Smith (1997), attempted to refine the Two-Component Theory of Aspect to account for some of the idiosyncrasies of Mandarin Chinese using a corpus-based approach. Some other researchers have tapped into certain problematic categories of verbs (e.g., Hay, Kennedy, \& Levin, 1999; Rappaport Hovav \& Levin, 2010) without attempting a comprehensive description of any aspectual system.

In her discussion of aspect, Smith (1997) argued that the cognitive abilities of humans are the basis for aspectual categories. In other words, they are not language dependent. She believes that "aspect is a semantic domain which is expressed in linguistic categories. Aspectual meanings are grammaticised through viewpoint and situation type categories" (1997, p. 5). She divided the aspectual system into two components: overt viewpoint aspect and covert situation aspect. Overtly expressed viewpoint aspect is manifested through verbal forms, auxiliaries, inflections, and particles, while covert situation categories involve semantic aspects of the situation at hand, which is controlled by the verb and its arguments. Situation types are described in terms of the three parameters of dynamicity, telicity, and instantaneity. The Two-Component Theory of Aspect is based on finding a correlation between a situation type on the one hand and a viewpoint on the other (Smith, 1997).

Situation Type. Aspectual meaning applies to sentences, and it is conveyed by the verb along with its arguments. Verbs and the arguments related to them have been referred to by Smith as verb constellations (1997, p. 2). These verb constellations express different situation types. Nevertheless, it is worth noting that adverbials, which are typically adjuncts, also play a role in the interpretation of situation types (Smith, 1997).

The situation types employed in Smith's Two-Component Theory of Aspect were derived from Vendler's (1957) semantic classification of verbs. Vendler (1957) proposed a categorisation of the time schemata of verbs, or in other words, a temporal semantic classification of verbs and the situations they describe. Accordingly, he classified verbs into activities, accomplishments, states, and achievements. Activity verbs are continuous in nature without a clear end or beginning point, while accomplishment verbs are continuous but with a natural ending point. State verbs, on the other hand, exist for some time, and achievement verbs happen instantaneously (Vendler, 1957). Smith (1997) adopted and adapted Vendler's (1957) taxonomy classifying verbs into five categories by adding the category of semelfactives to Vendler's verb types in reference to verbs that are instantaneous and occur only once (e.g., knock).

The five situation types are described using the features [+/-dynamic], [+/-telic], and [+/-instantaneous]. The two features dynamic and instantaneous are poles on two different graded scales. The feature dynamic is at the opposite end of the feature static, and the feature instantaneous is at the opposite end of the feature durative. Some scholars prefer to use static instead of dynamic, and durative instead of instantaneous with opposite values (Smith, 1997). In this paper, however, the researcher maintains the features dynamic, instantaneous, and telic as indicated in Table 1 below partly adopting the convention followed by Anderson (1991) and Shirai (2000).

Dynamic situations are those that involve motion, telic events are situations that have natural endpoints, and instantaneous situations are those that are not durative in nature and occur instantaneously (Smith, 1997). Accordingly, States are [-dynamic, -instantaneous, -telic]; Activities are [+dynamic, -instantaneous, -telic]; Accomplishments are [+dynamic, -instantaneous, +telic]; Achievements are [+dynamic, +instantaneous, +telic], and Semelfactives are [+dynamic, +instantaneous, -telic].

Further, Smith (1997) has detailed the semantic characteristics and temporal schemata of each situation type. States are situation types that hold for a period of time (e.g., love), while activities are mental or physical processes that do not have inherent endpoints (e.g., swim). Accomplishments are processes that have outcomes or end in the completion of the process by a change of state (e.g., write a letter). Achievements, on the other hand, are instantaneous, and they also entail a change of state (e.g., win). Finally, semelfactives are instantaneous "single-stage events" (Smith, 1997, p. 29), in other words, they occur only once (e.g., blink). However, since aspectual meaning applies to sentences/utterances, the context within which each situation occurs plays a 
Table 1

Smith's (1997) situation types described using the features [+/-dynamic], [+/- telic], and [+/-instantaneous]

\begin{tabular}{lcccl}
\hline Situation Types & Dynamic & Instantaneous & Telic & Examples \\
\hline States & - & - & - & Know, like, love \\
Activities & + & - & - & Play, read, walk \\
Accomplishments & + & - & + & Make a chair, watch the movie \\
Achievements & + & + & + & Drop, die, win the race \\
Semelfactives & + & + & - & Jump, knock \\
\hline
\end{tabular}

crucial role in determining its situation type.

Viewpoint Aspect. The second component of Smith's (1997) theory is viewpoint aspect. She drew an analogy between viewpoint aspect and a camera lens explaining that "situations are the objects on which viewpoint lenses are trained" (1997, p. 61). Thus, as Smith (1997) claimed, viewpoints are essential to detecting situation types. They are typically encoded morphologically (Smith, 1997). This may involve using auxiliaries, inflections, or particles (Anderson, 1991; Comrie, 1976).

Further, Smith (1997) has classified viewpoint aspect into perfective, imperfective, and neutral. Typically, perfective aspect has an outside viewpoint to a situation including its beginning and end without considering its internal structure, while imperfective aspect has an internal viewpoint to the situation and considers its internal structure excluding its beginning and end. Neutral viewpoint, on the other hand, focuses on the beginning of the event and some of its stages.

Perfective viewpoint aspect, as mentioned above, views a situation including its beginning and end. It encompasses the situation as a whole without considering its internal stages. Perfective situation types are completed events. Smith (1997) has distinguished between marked and unmarked perfective viewpoint. In this sense, unmarked perfective viewpoint sees situations as closed, which means that it includes their beginning and end points. Marked perfective viewpoint aspect; on the other hand, involves cases in which the situation aspect is a state. In this case, the end of the event is not clear.

Imperfective viewpoint aspect only considers a portion of the situation. It does not view situations as completed events. Unlike perfective viewpoint, imperfective viewpoint does not consider the beginning and end points of a situation. A distinction between marked and unmarked imperfective viewpoints has also been made by Smith (1997). Unmarked imperfective viewpoint considers situations from within by focusing on their internal stages. Conversely, marked imperfective viewpoint views "preliminary stages of events or the resultant stages of telic events” (Smith, 1997, p. 73). In this case, the imperfective views a situation externally.

The third type of viewpoint aspect, referred to as neutral viewpoint, was proposed and argued for by Smith (1997) to describe sentences that accept both open and closed interpretations. She proposed the category of neutral viewpoint to account for some sentences she came across in her description of the aspectual system of Mandarin Chinese. However, Xiao and McEnery (2004), who conducted a corpus-based study on the aspectual system of Mandarin Chinese, have argued that such a category is not necessary since all the instances they came across in the data were either perfective or imperfective. For this reason, neutral viewpoint will not be addressed in the current study.

\section{Materials and Methods}

The study was a descriptive study that relied on the analysis of data within a selected framework (i.e., Smith, 1997). This section addresses the data and the procedures of the study.

\section{Data}

Since the study investigated aspectual meanings associated with the particle qad in MSA, the data consisted of 
examples in which qad constructions were used. The examples were based on examples obtained from existing literature relevant to the topic at hand, in addition to some typical examples that were selected by the researcher, who is a native speaker of Arabic. The items that were analysed may be used in both spoken and written forms of MSA. However, they are more likely to occur in the written variety, since-as explained above-MSA is the variety of Arabic currently used in the Arab world in writing, public speaking, the media, and education (Ryding, 2005). Even though MSA is used in spoken form to perform certain functions, everyday communication in the Arab world is typically carried out using spoken varieties that may vary greatly from one geographical location to another (Ryding, 2005).

After the examples were selected by the researcher, several faculty members specialised in linguistics and/or translation were consulted to render the English translations of the Arabic examples. The purpose of providing the English translation of each example was two-fold; the translations served to explain the meanings of the Arabic examples to non-native speakers of Arabic, however they mainly served the purpose of helping the researcher gauge the differences in meaning in the analysis of viewpoint and situation type. It is worth noting at this point that the translations provided below, which are based on the translations proposed by the faculty members who were consulted, are supported by the discussion of Gadalla (2017) above.

Moreover, the examples were also categorised under the following four construction patterns following Gadalla (2017):
1. qad + kāna + non-past form of verb
2. qad + past form of verb
3. kāna +qad + past form of verb
4. sa-/sawfa + non-past form of kāna + qad + past form of verb

\section{Procedure}

To investigate the semantics of the Arabic aspectual marker qad, examples that contain qad were analysed in terms of the components of the Two-Component Theory of Aspect (Smith, 1997), namely viewpoint and situation type. Viewpoint aspect was looked into first followed by further analysis of perfective and imperfective viewpoint combinations with the five situation types identified by Smith (1997).

\section{Results and Discussion}

In this section, the occurrence of the Arabic aspectual marker qad in different constructions is discussed in light of Smith's (1997) Two-Component Theory of Aspect. The two viewpoint distinctions are examined first, followed by an analysis of the situation types conveyed by different examples in the data.

It is worth noting at this point that the tense/aspect system in Arabic is not as fixed as that of other languages like English since a degree of overlap between the two systems exists (Ryding, 2005). Furthermore, "there is no one to one relationship between forms expressing tense and aspect in English and Arabic” (Sieny, 1986, p. 50).

\section{Viewpoint}

As far as viewpoint is concerned, Smith (1997) distinguished between imperfective and perfective viewpoints within her Two-Component Theory of Aspect. As presented above, the functions of qad are either temporal/ aspectual or modal. Qad typically prefers the temporal/aspectual function when it occurs with past verb forms. On the other hand, when it combines with non-past verb forms, it typically indicates modality (i.e., possibility or probability). Consider the following examples:
(9) qad
ya 'rifu
al-jawāb
may/migh
knows he
the-answer
He may/might know the answer. 
$\begin{array}{lll}\text { (10) la-qad } & \text { akmaltu } & \text { qira'ata al-kitāb } \\ \text { la-qad } & \text { completed-I } & \text { reading the-book }\end{array}$

I have completed reading the book.

(11) sa-yakūnu qad kataba al-risālata ghadan will be he qad wrote he the-letter tomorrow

He will have (already) written the letter tomorrow.

Example (9) includes qad with the non-past verb ya 'rifu 'he knows'. In this example, the particle qad performs the function of modality indicating possibility. Examples (10) and (11), on the other hand, include instances of qad as an aspectual marker. Both examples portray events in terms of perfective aspect since the events are viewed externally as complete units. In example (10), the past form of the Arabic verb akmaltu 'I completed' is used with qad. In (11), qad is used in the construction that follows the pattern sa- + non-past form of käna + qad + past form of verb in a construction that is comparable to the English future perfect tense.

However, as mentioned above, qad also occurs in constructions that follow the pattern qad + kāna + non-past form of verb. In such cases, the imperfective viewpoint may be expressed. For example:

$\begin{array}{llll}\text { (12) la-qad } & \text { kānat } & \text { tal'abu } & \text { bil-kurati } \\ \text { la-qad } & \text { was she } & \text { plays she } & \text { with the-ball }\end{array}$

She was playing with the ball.

In example (12), the construction qad + kāna + non-past form of verb is used expressing the imperfective viewpoint with the verb tal 'abu 'she plays'.

\section{Situation Types}

Smith's (1997) five-way verb classification was applied to different situations to determine typical viewpointsituation type combinations. Consider the following constructions, which follow the pattern qad + kāna + nonpast verb form:

$\begin{array}{llll}\text { la-qad } & \text { kānat } & \text { ta'rifu } & \text { al-haquata } \\ \text { la-qad } & \text { was she } & \text { knows she } & \text { the-truth }\end{array}$

She has/had known the truth. OR She knew the truth.

(state)

(14) la-qad kānat tal'abu bil-dumyati

la-qad was she plays she with the-doll

She was playing with the doll.

(activity)

(15) la-qad kānat tuhaḍ̣̂iru al-ḥaqübata

la-qad was she prepares she the-bag

She was preparing her bag.

(16) *la-qad kānat tafüzu fĩ al-sibāq

la-qad was she wins shein the-race

*She has/had been winning the race.

(achievement)

(17) la-qad kānat taqfizu

la-qad was she jumps she

She was jumping.

(semelfactive)

Example (13) conveys the perfective viewpoint with the state situation type expressed by the verb ta 'rifu 'she knows'. Example (14), on the other hand, conveys the imperfective viewpoint with the activity situation type represented by the verb tal 'abu 'she plays'. The same applies to example (15), which also conveys imperfectivity 
in the accomplishment situation type expressed by the situation tuhaddiru al-haqībata 'she prepares the bag'. Example (16) is unsuccessful as indicated by the asterisks. The Arabic non-past form of the achievement situation type tafüzu fí al-sibāq 'she wins the race' is not successful when combined with qad + kāna. The example fails to covey the sense of winning a race since it anomalously conveys progression with a situation that is inherently [+dynamic, +instantaneous, +telic]. Finally, example (17) is unsuccessful in portraying the semelfactive situation type conveyed by the verb taqfizu 'she jumps' since it conveys an imperfective sense of activity instead (i.e., repeated jumping).

Therefore, in constructions that follow the pattern qad + kāna + non-past verb form, aspectual qad conveys the perfective viewpoint with states, while it conveys the imperfective viewpoint with activities and accomplishments. As for achievements and semelfactives, the analysis indicated that they are unsuccessful in this particular qad construction. Achievements are anomalous, while semelfactives transform into activities.

Now consider the following examples grouped according to situation types, which follow the three construction patterns qad + past form of verb, kāna + qad + past form of verb, and sa-/sawfa + non-past form of kāna + qad + past form of verb:

\section{A. Situation type: States}

$\begin{array}{llll}\text { la-qad } & \text { a jabahu } & \text { manzaru } & \text { al-bahr } \\ \text { la-qad } & \text { liked he } & \text { view } & \text { the-sea }\end{array}$

She was jumping.

(19) kāna

qad

$\begin{array}{llll}\text { qad } & \text { a jabahu } & \text { manzaru } & \text { al-bahr } \\ \text { qad } & \text { liked he } & \text { view } & \text { the-sea }\end{array}$

He had liked the view of the sea. OR He liked the view of the sea.

\begin{tabular}{|c|c|c|}
\hline $\begin{array}{l}{ }^{*} \text { sa-yakūnu } \\
\text { will be he }\end{array}$ & $\begin{array}{l}\text { qad } \\
\text { gad }\end{array}$ & $\begin{array}{l}\text { a jabahu } \\
\text { liked he }\end{array}$ \\
\hline
\end{tabular}

*He will have liked the view of the sea.

Examples (18)-(20) contain the state situation type expressed by the past form of the verb a 'jabahu 'he liked'. In examples (18) and (19), which follow the patterns qad + past form of verb and kāna + qad + past form of verb respectively, the viewpoint is perfective indicating completed situations that are viewed as closed events. The two examples maintain the typical feature matrix of states [-dynamic, -instantaneous, -telic]. Example (20), on the other hand, is unsuccessful since the state was not properly conveyed in the future time reference entailed by the construction pattern sa-/sawfa + non-past form of käna + qad + past form of verb.

B. Situation type: Activities

(21) la-qad la-qad

la $i b a$ played he

$$
\begin{array}{ll}
f \bar{l} & \text { al-hadiqati } \\
\text { in } & \text { the-park }
\end{array}
$$

He has played in the park. OR He played in the park.

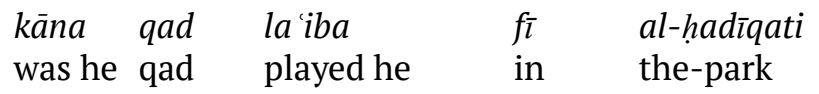

He had played in the park.

$\begin{array}{llll}\text { sa-yakūnu } & \text { qad la iba } & f_{\bar{l}} & \text { al-hadīqati } \\ \text { will be } & \text { qad played he } & \text { in } & \text { the-park }\end{array}$

He will have played in the park.

Examples (21)-(23) contain the activity situation type expressed by the past form of the verb la 'iba 'he played'. All the examples successfully convey the perfective viewpoint dealing with the activity as a completed event and preserving the features of activities [+dynamic, -instantaneous, -telic]. 
C. Situation type: Accomplishments

$\begin{array}{lll}\text { (24) la-qad haddarat al-haqïbata } & \\ \text { la-qad } & \text { packed she the-bag }\end{array}$

She has prepared her bag. OR She prepared her bag.

(25)

$\begin{array}{llll}k a \bar{n} n a t & \text { qad } & \text { haddarat } & \text { al-haqïbata } \\ \text { was she } & \text { qad } & \text { packed she } & \text { the-bag }\end{array}$

She had prepared her bag.

(26) sa-takūnu qad hadḍarat al-haqübata will be she qad packed she the-bag

She will have prepared her bag.

Examples (24)-(26) contain the accomplishment situation type expressed by the verb constellation hadarat al-haqïbata 'she packed the bag'. According to Smith (1997), accomplishments carry the features [+dynamic, -instantaneous, +telic], which is supported by the three examples above since they convey the situation as a complete event within a perfective viewpoint.

D. Situation type: Achievements

(27) la-qad la-qad

$\begin{array}{lll}\text { fāzat } & f_{\bar{l}} & a l-s i b a \bar{q} \\ \text { won she } & \text { in } & \text { the-race }\end{array}$

She has won the race. OR She won the race.

(28) kānat

was she qad

qad fäzat

fì $\quad$ al-sibāq

She had won the race.

(29)

$\begin{array}{lllll}\text { sa-takūnu } & \text { qad } & \text { fäzat } & f_{\bar{l}} & \text { al-sibāq } \\ \text { will be she } & \text { qad } & \text { won she } & \text { in } & \text { the-race }\end{array}$

She will have won the race.

Examples (27)-(29) contain the achievement situation type expressed by the verb constellation fäzat fí al-sibāq 'she won the race'. The situation is inherently [+dynamic, +instantaneous, +telic], which is supported by the perfective viewpoint that is conveyed in the three examples.

E. Situation type: Semelfactives

(30) la-qad

$$
\text { qafaza al-walad }
$$

la-qad jumped he the-boy

The boy jumped.

(31) kāna

$$
\text { qad qafaza al-walad }
$$

was-he qad jumped he the-boy

The boy jumped.
sa-yakūnu
qad qafaza
al-walad
will be he
qad jumped he
the-boy

The boy will have jumped.

Examples (30)-(32) contain the semelfactive situation type expressed by the verb constellation qafaza al-walad 'the boy jumped'. The three examples convey the perfective viewpoint with semelfactive situations that are characterised by the feature matrix [+dynamic, +instantaneous, -telic]. 
Based on the discussion and examples above, it was noted that the imperfective viewpoint was more typical with the construction qad + kāna + non-past verb form (See Table 2), while the perfective viewpoint prevailed with the two construction patterns qad + past form of verb and kāna + qad + past form of verb (See Table 3). However, although the perfective viewpoint was successfully realised with all five situation types in the latter two construction patterns, the imperfective viewpoint in the construction qad + kāna + non-past verb form was only realised in two situation types; namely, activities and accomplishments. When states were used in the construction qad + kāna + non-past verb form, a perfective viewpoint was conveyed. As for achievements, they were unsuccessful in the construction qad + kāna + non-past verb form, while semelfactives were transformed into activities because they conveyed the meaning of dynamicity.

Table 2

Summary of the combinations of viewpoint aspect and situation types in the construction qad + kāna + non-past verb form

\begin{tabular}{lcc}
\hline Situation Type & Perfective Viewpoint & Imperfective Viewpoint \\
\hline States & $\sqrt{ }$ & $\sqrt{ }$ \\
Activities & & $\sqrt{ }$ \\
Accomplishments & - & - \\
Achievements & - & - \\
Semelfactives & - & \\
\hline
\end{tabular}

Table 3

Summary of the combinations of viewpoint aspect and situation types in the constructions qad + past form of verb and kāna + qad + past form of verb

\begin{tabular}{lcc}
\hline Situation Type & Perfective Viewpoint & Imperfective Viewpoint \\
\hline States & $\sqrt{ }$ \\
Activities & $\sqrt{ }$ \\
Accomplishments & $\sqrt{ }$ \\
Achievements & $\sqrt{ }$ \\
Semelfactives & & \\
\hline
\end{tabular}

As for the fourth construction addressed in this study, which follows the pattern sa-/sawfa + non-past form of kāna + qad + past form of verb, the analysis found that it conveyed the perfective viewpoint with activities, accomplishments, achievements, and semelfactives. It was not successful with states (See Table 4), which may be due to the future reference entailed by this particular construction pattern.

Table 4

Summary of the combinations of viewpoint aspect and situation types in the construction sa-/sawfa + non-past form of kāna + qad + past form of verb

\begin{tabular}{lcc}
\hline Situation Type & Perfective Viewpoint & Imperfective Viewpoint \\
\hline States & - & \\
Activities & $\checkmark$ & \\
Accomplishments & $\checkmark$ & \\
Achievements & $\sqrt{ }$ & \\
Semelfactives & $\checkmark$ & \\
\hline
\end{tabular}

\section{Conclusion}

This paper set out to investigate the Arabic aspectual particle qad within the framework of Smith's (1997) TwoComponent Theory of Aspect. The Two-Component Theory accounts for situation types as well as viewpoint 
aspects in the interpretation of aspectual meaning. The particle was analysed in four different construction patterns in terms of both situation types and viewpoints. It was found to convey perfective as well as imperfective viewpoints in MSA. Some situation types were found to behave consistently, irrespective of the viewpoint, while others varied. States were found to be typically perfective with qad constructions with the exception of constructions that entail future reference. Activities and accomplishments were both successfully conveyed by perfective and imperfective $q a d$, while achievements were only realised perfectively. This is probably due to the nature of achievement verbs which are [+dynamic, +instantaneous, +telic] conveying instantaneous meaning, thereby forcing us to view them as completed events. As for semelfactives, they were only conveyed perfectively since they were transformed into imperfective activities with imperfective qad. Nevertheless, the verb constellation, as well as other adjuncts that may be present in the sentence, play a significant role in determining viewpoint since the semantics of the verb contributes to temporal and aspectual meanings.

I believe that the findings have pedagogical implications that are relevant to the teaching of translation and training of translators. If translation students are made aware of the differences between the aspectual meanings of English and Arabic, and realise the different viewpoints Arabic can express using the particle qad, their performance on translation tasks will probably improve because they will be able to choose better structural equivalents to convey the senses expressed in the source text.

Further, a complete corpus-based description of the aspectual system of Arabic can be conducted in light of Smith's (1997) Two-Component Theory of Aspect, since none have been carried out to the best of the author's knowledge. The findings of such a description will contribute to enriching previous research in the field in addition to enhancing further understanding of aspectual meaning in MSA.

\section{References}

Anderson, R.(1991). Developmental sequences: The emergence of aspect marking in second language acquisition. In T. Huebner \& C. Ferguson (Eds.), Cross Currents in Second Language Acquisition and Linguistic Theory (Vol. 2, pp. 305-324). Amsterdam, the Netherlands: John Benjamins Publishing Company.

Badawi, E., Carter, M. G., \& Gully, A. (2016). Modern written Arabic: A comprehensive grammar (2nd ed.). London, UK: Routledge.

Bahloul, M. (2008). Structure and function of the Arabic verb. London, UK: Routledge.

Caspari, C. P. (1898). The grammar of the Arabic language (W. Wright, Trans.). Cambridge, UK: Cambridge University Press.

Comrie, B. (1976). Aspect: An introduction to the study of verbal aspect and related problems. Cambridge, UK: Cambridge University Press.

Cruse, A. (2011). Meaning in language: An introduction to semantics and pragmatics (3rd ed.). Oxford, UK: Oxford University Press.

Csirmaz, A. (2008). Particles and a two-component theory of aspect. In K. Kiss (Ed.), Event Structure and the Left Periphery: Studies on Hungarian (pp. 107-128). Dordrecht, the Netherlands: Springer. doi:10.1007/978$1-4020-4755-8$ - 6

Dahl, O. (1985). Tense and aspect systems. Oxford, UK: Basil Blackwell Ltd.

Dragoy, O., Virfel, E., Yurchenko, A., \& Bastiaanse, R. (2019). Aspect and tense attrition in Russian-German bilingual speakers. International Journal of Bilingualism, 23(1), 275-295. doi:10.1177/1367006917728388

Farghal, M. (2018). Present perfect or simple past? The function of qad in English-into-Arabic translation. Babel, 64(5/6), 710-733. doi:10.1075/babel.00063.far

Fassi Fehri, A. (2012). Key features and parameters in Arabic grammar. Amsterdam, the Netherlands: John Benjamins Publishing Company. doi: 10.1075/la.182

Gadalla, H. (2006). Arabic imperfect verbs in translation: A corpus study of English renderings. Meta, 51(1), 5171. doi:10.7202/012993ar

Gadalla, H. (2017). Translating tenses in Arabic-English and English-Arabic contexts. Newcastle upon Tyne, UK: Cambridge Scholars Publishing.

González, P., \& Hernández, L. Q. (2018). Inherent aspect and L1 transfer in the L2 acquisition of Spanish grammatical aspect. The Modern Language Journal, 102(3), 611-625. doi: 10.1111/modl.12502

Hamm, F., \& Bott, O. (2016). Tense and aspect. In E. Zalta (Ed.), The Stanford Encyclopedia of Philosophy. Retrieved 
from https://plato.stanford.edu/entries/tense-aspect/

Hay, J., Kennedy, C., \& Levin, B. (1999). Scalar structure underlies telicity in ‘degree achievements'. In T. Mathews \& D. Strolovitch (Eds.), SALT IX (pp. 127-144). Ithaca, NY: CLC Publications. doi:10.3765/salt.v9i0.2833

Haywood, J. A., \& Nahmad, H. M. (1965). A new Arabic grammar of the written language (2nd ed.). London, UK: Lund Humphries Publishers Ltd.

Izquierdo, J., \& Kihlstedt, M. (2019). L2 imperfective functions with verb types in written narratives: A crosssectional study with instructed Hispanophone learners of French. The Modern Language Journal, 103(1), 291307. doi:10.1111/modl.12539

Kanwit, M. (2017). What we gain by combining variationist and concept-oriented approaches: The case of acquiring Spanish future-time expression. Language Learning: A Journal of Research in Language Studies, 67(2), 461-498. doi:10.1111/lang.12234

Li, P., \& Shirai, Y. (2000). The acquisition of lexical and grammatical aspect. Berlin, Germany: Mouton de Gruyter. doi:10.1515/9783110800715

Michalski, M. (2011). On the functions of the verbal particle la-qad in modern standard Arabic. Folia Orientalia, 48, 99-113.

Peck, J., Lin, J., \& Sun, C. (2013). Aspectual classification of Mandarin Chinese verbs: A perspective of scale structure. Language and Linguistics, 14(4), 663-700.

Rappaport Hovav, M., \& Levin, B. (2010). Reflections on manner/result complementarity. In M. Rappaport Hovav, E. Doron \& I. Sichel (Eds.), Lexical Semantics, Syntax, and Event Structure (pp. 21-38). Oxford, UK: Oxford University Press. doi:10.1093/acprof:oso/9780199544325.003.0002

Ryding, K. (2005). A reference grammar of modern standard Arabic. Cambridge, UK: Cambridge University Press. doi:10.1017/CBO9780511486975

Shirai, Y. (2000). The semantics of the Japanese imperfective -teiru: An integrative approach. Journal of Pragmatics, 32, 327-361. doi:10.1016/S0378-2166(99)00051-X

Sieny, M. (1986). Tense and aspect in English and Arabic: Communicative-functional equivalence. Journal of the College of Arts King Saud University, 13(1), 41-59.

Smith, C. (1997). The parameter of aspect (2nd ed.). Dordrecht, the Netherlands: Kluwer Academic Publishers. doi:10.1007/978-94-011-5606-6

Vendler, Z. (1957). Verbs and times. The Philosophical Review, 66(2), 143-160. doi:10.2307/2182371

Xiao, R., \& McEnery, T. (2004). Aspect in Mandarin Chinese: A corpus-based study. Amsterdam, the Netherlands: John Benjamins Publishing Company. doi:10.1075/slcs.73 